\title{
Diagnóstico da qualidade da água de açudes utilizados na dessedentação animal do Vale do Taquari/RS
}

A água de boa qualidade é essencial para o desenvolvimento e sobrevivência dos seres vivos. No meio rural a principal forma de abastecimento ocorre por poços próprios e nascentes. A água destinada ao consumo humano deve atender ao padrão de potabilidade estipulado pela legislação, e quando destinada à dessedentação animal deve atender aos requisitos de qualidade estabelecidos em lei. O estudo objetivou avaliar as características físico-químicas e microbiológicas da água de açude destinada ao consumo animal de propriedades rurais com produção leiteira da região na região do Vale do Taquari, Rio Grande do Sul, Brasil. Do total de 104 propriedades rurais, foram coletadas amostras de 19 açudes em diversos municípios do Vale do Taquari, destinados ao abastecimento de gado leiteiro. Foram coletadas e analisadas amostras de água por meio de parâmetros físico-químicos e microbiológicos com o uso do Kit de Potabilidade Alfakit ${ }^{\circledR}$ e equipamento de rápida leitura. Os parâmetros cloreto e ferro enquadram-se nos valores permitidos pela legislação e os demais, como oxigênio dissolvido, pH, turbidez, cor, sólidos dissolvidos totais e coliformes termotolerantes estão em desacordo. Conclui-se assim que, quase todas as amostras de água analisadas ( $\mathrm{n}=14$ ) não estão de acordo com os valores estipulados pela legislação consultada. Desse modo, há a necessidade de melhor manejo e monitoramento dos açudes, bem como a elaboração e execução de um programa de educação ambiental, para capacitar e conscientizar os produtores rurais.

\section{Diagnostic of the water quality reservoirs used in animal feed in Taquari Valley/RS}

\begin{abstract}
Good quality water is essential for the development and survival of living beings. In rural areas the main form of supply occurs by own wells and springs. The water intended for human consumption must comply with the drinking standard stipulated by the legislation, and when destined to the animal watering it must meet the quality requirements established by law. The objective of this study was to evaluate the physicochemical and microbiological characteristics of weir water for animal consumption of dairy farms in the region of Vale do Taquari, Rio Grande do Sul, Brazil. From the total of 104 rural properties, samples were collected from 19 ponds in several municipalities of Vale do Taquari, destined to supply dairy cattle. Water samples were collected and analyzed by physical-chemical and microbiological parameters using the Alfakit ${ }^{\circledR}$ Potability Kit and fast reading equipment. The parameters chloride and iron are in accordance with the values allowed by the legislation and the others, such as dissolved oxygen, $\mathrm{pH}$, turbidity, color, total dissolved solids and thermotolerant coliforms are in disagreement. It is concluded that almost all water samples analyzed $(\mathrm{n}=14)$ do not agree with the values stipulated by the legislation consulted. In this way, there is a need for better management and monitoring of dams, as well as the elaboration and execution of an environmental education program, to train and raise awareness among rural producers.
\end{abstract}

Keywords: Environmental analysis; Water analysis; Rural producer.

Topic: Engenharia Ambiental

Reviewed anonymously in the process of blind peer.
Received: $14 / 12 / 2017$

Approved: 24/01/2018
Jaqueline de Bortoli

Universidade Federal de Pelotas, Brasil

http://lattes.cnpq.br/1081999900288101

ibortoli@universo.univates.br

Gabriela Dahm

Universidade do Vale do Taquari, Brasil

http://lattes.cnpq.br/6636887201429936

gabriela_dahm@hotmail.com

Gustavo Rodrigo da Silva

Universidade do Vale do Taquari, Brasil

http://lattes.cnpq.br/4580848075797987

gustavo.silva1@univates.br

DOI: 10.6008/CBPC2179-6858.2018.002.0018

\author{
Mônica Jachetti Maciel (1D) \\ Universidade do Vale do Taquari, Brasil \\ http://lattes.cnpq.br/2575088289818885 \\ http://orcid.org/0000-0002-6863-2181 \\ monicajm@univates.br \\ Claudete Rempel (iD) \\ Universidade do Vale do Taquari, Brasil \\ http://lattes.cnpq.br/8340497822227462 \\ http://orcid.org/0000-0001-8573-0237 \\ crempel@univates.br
}

\section{Referencing this:}

BORTOLI, J.; DAHM, G.; SILVA, G. R.; MACIEL, M. J.; REMPEL, C. Diagnóstico da qualidade da água de açudes utilizados na dessedentação animal do Vale do Taquari/RS. Revista Ibero Americana de Ciências Ambientais, v.9, n.2, p.207-217, 2018. DOI: http://doi.org/10.6008/CBPC2179-6858.2018.002.0018 


\section{INTRODUÇÃO}

A água é um dos mais importantes recursos naturais da Terra, pois garante o equilíbrio do ecossistema e é vital para todos os seres vivos, pode ser utilizada de diversas formas, na dessedentação humana e animal, na indústria, na irrigação, na navegação e na pesca. A água constitui um elemento essencial nas atividades econômicas do setor primário como agricultura e pecuária (LIMA et al., 2008). No meio rural, a água fornecida aos animais, normalmente, provém de fontes naturais como nascentes, arroios, córregos, banhados e açudes, devido à praticidade e baixo custo (AMARAL et al., 2003; DIAS, 2006). Açude é uma barreira artificial que tem como objetivo reter grandes quantidades de água e promover o abastecimento hídrico em zonas residenciais, agrícolas e industriais, podendo também produzir energia elétrica (NASCIMENTO, 2012).

A água consumida pelos bovinos reflete no desempenho produtivo e no seu bem-estar (TAVARES, 2012). Se a água for de baixa qualidade pode transmitir numerosos agentes infecciosos e ocasionar gastroenterites, hepatites, infecções respiratórias e generalizadas (CERQUEIRA et al., 2006). Atualmente existem poucos estudos sobre a qualidade da água destinada ao rebanho de leite e o impacto gerado na produção de leite, bem como a sanidade animal, havendo maior preocupação apenas com aquela destinada ao abastecimento humano.

A Resolução (RDC) do Conselho Nacional do Meio Ambiente (CONAMA) № 357 de 2005 (BRASIL, 2005) classifica e decreta as diretrizes ambientais para o enquadramento dos corpos de águas superficiais, tais como os açudes, que podem ser utilizados na dessedentação animal, desde que apresente parâmetros físico-químicos e microbiológicos conforme a descrição da RDC. Os açudes pertencem a classe 3, cujos principais parâmetros a serem analisados são coliformes termotolerantes, oxigênio dissolvido, turbidez, cor e pH. O monitoramento por meio desses parâmetros é essencial para a saúde animal e para diagnosticar as possíveis fontes de poluição que interferem na qualidade da água (LIMA et al., 2008).

Os animais que tem acesso direto às águas superficiais, como os açudes acabam contaminando o local com as suas fezes, favorecendo o aumento de coliformes termotolerantes (COIMBRA, 2007). Além disso, o acesso direto de bovinos em fontes naturais ocasiona maior degradação do ambiente comprometendo a qualidade da água. O oxigênio dissolvido é um elemento essencial para os organismos aeróbicos existentes na água, caso seja totalmente consumido, haverá condições anaeróbicas ao ambiente e a geração de condições redutoras, aumentando a toxicidade de elementos químicos, como os metais, por exemplo, que ficarão mais solúveis (PEREIRA, 2004).

$\mathrm{O}$ pH é um dos parâmetros físico-químicos da água mais importantes de ser avaliado, pois a partir dele se pode fazer uma avaliação do uso desta água para a limpeza do ambiente relacionando-o com os tipos de detergentes (RUZANTE et al., 2001). Além disso, o pH é um fator relevante para a sobrevivência de organismos existentes neste meio (VON SPERLING, 2005). A turbidez da água refere-se à presença de matéria particulada em suspensão, como matéria orgânica, inorgânica, fitoplâncton e outros microrganismos, mas ela expressa a transparência da água (HELLER et al., 2006). Os sólidos dissolvidos, seja por fatores naturais 
ou antrópicos, como pela decomposição da matéria orgânica morta, ferro, manganês, resíduos industriais ou esgotos domésticos constituem a cor da água (VON SPERLING, 2005).

A região do Vale do Taquari, formada por 36 municípios com forte atividade leiteira no meio rural, dispõe de açudes para diversos fins, como uso pesqueiro, irrigação, lazer e principalmente para o uso de dessedentação animal. Considerando a relevância socioeconômica que a bovinocultura de leite exerce na região do Vale do Taquari/RS, além da carência em publicações relacionadas à qualidade da água ingerida pelos animais em açudes, o presente estudo teve por objetivo avaliar a qualidade físico-química e microbiológica da água de 19 açudes na região do Vale do Taquari, Rio Grande do Sul, Brasil, realizando um comparativo entre os parâmetros determinados pela Resolução CONAMA nº 357 de 17 de março de 2005 (BRASIL, 2005) a partir da classificação da água da complexidade ou não de seu tratamento para fins de consumo animal.

\section{METODOLOGIA}

O Vale do Taquari, formado por 36 municípios, conforme apresenta a Figura 1, está localizado na região central do Rio Grande do Sul-Brasil, apresenta uma área total de 4.826,7 km², onde residem 348.435 habitantes (IBGE, 2015). Esta população é formada por diversas etnias, origem alemã, italiana e açoriana. Além disso, destacam-se 43 mil produtores rurais, envolvidos em pequenas e médias propriedades no meio rural, essas famílias dedicam-se à agricultura e pecuária colocando a região do Vale do Taquari em segunda posição na produtividade rural. Além do setor agropecuário, outros municípios estão inseridos nas atividades de indústria e comércio.

O estudo foi realizado em propriedades rurais com produção de leite em 14 municípios do Vale do Taquari/RS (Figura 1). As unidades amostrais foram definidas levando-se em consideração o número de estabelecimentos rurais existentes em cada município, a partir dos dados do último Censo Agropecuário do IBGE (2006) de modo que a amostra tivesse 95\% de confiança. As Secretarias de Agricultura e Empresa de Assistência Técnica e Extensão Rural (EMATER) dos municípios foram responsáveis por indicar às propriedades rurais participantes do estudo, em seguida, as atividades in loco deram início.

Para o desenvolvimento deste trabalho foi coletada uma amostra de água em frascos de vidro de $500 \mathrm{~mL}$ autoclavados de 19 açudes que são utilizados como fontes para dessedentação animal. Para realizar o procedimento de coleta, seguindo-se a metodologia proposta pelo Manual Prático de Análise de Água (FUNASA, 2004). Após, armazenadas, as amostras foram identificadas e acondicionadas em caixas térmicas contendo gelo sendo encaminhadas para os laboratórios para a realização das análises.

Para analisar os parâmetros físico-químicos: cloretos e ferro utilizou-se o Kit Básico de Potabilidade da Água (código 2693), AlfaKit ${ }^{\circledR}$, seguindo metodologia descrita pelo fabricante. Os parâmetros temperatura da água e oxigênio dissolvido foram analisados in loco. Os parâmetros como cor, pH, oxigênio dissolvido, temperatura da água e turbidez foram analisados com os equipamentos de rápida leitura da Digimed ${ }^{\circledR}$ e as análises de sólidos dissolvidos totais seguiu a metodologia da AOAC (1995). 


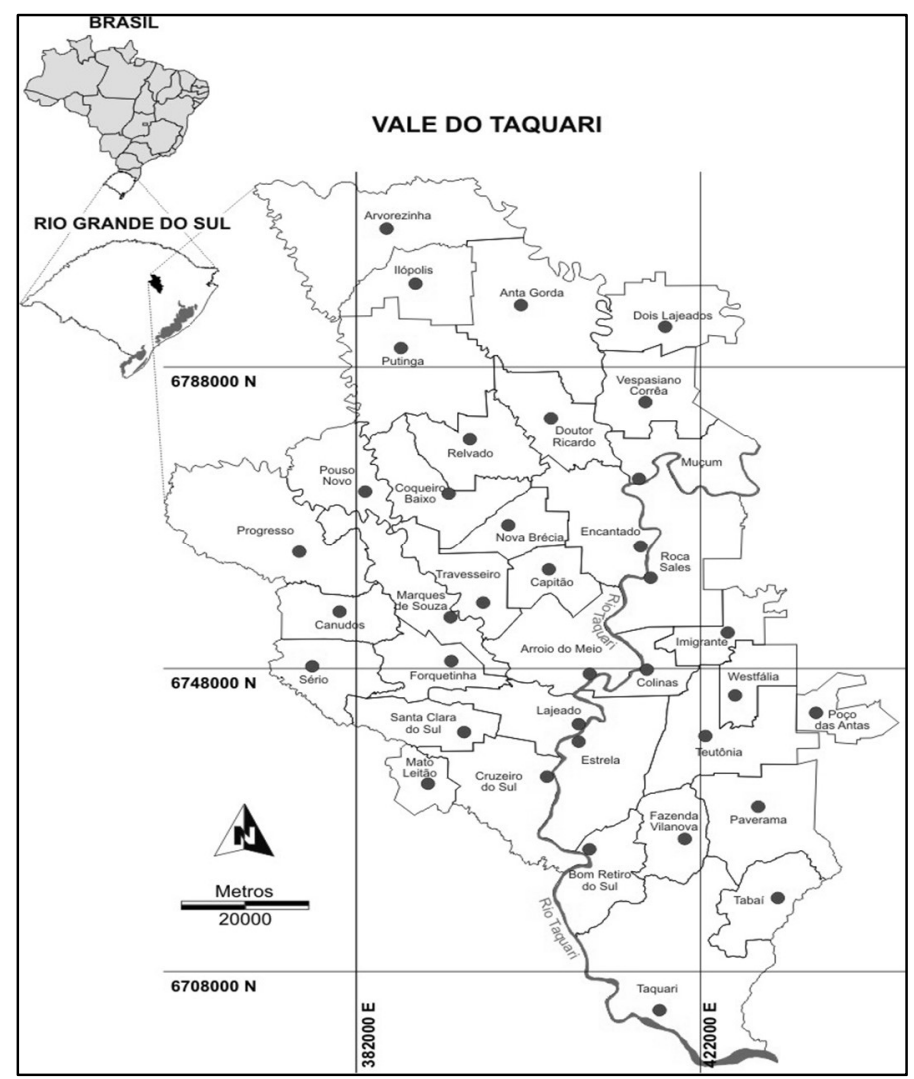

Figura 1: Mapa de localização da região do Vale do Taquari/RS/Brasil. Fonte: Eckhardt et al. (2013).

A análise microbiológica de coliformes totais (Enterobacter cloacae) e coliformes termotolerantes (Escherichia coli) seguiu a metodologia proposta pelo Kit Básico de Potabilidade da Água Alfakit ${ }^{\circledast}$ (código 2693). Para interpretação do resultado utilizou-se o contador de colônias (pontos vermelhos, azuis e violeta representam coliformes totais e pontos azuis e violetas representam coliformes termotolerantes). Para expressar o valor de Unidade Formadora de Colônia (UFC), multiplicou-se o fator de correlação (80) pelo valor encontrado em cada cartela. Todos os parâmetros foram analisados em triplicatas.

Os resultados obtidos foram organizados em planilhas no software Microsoft Excel ${ }^{\circledR} 2010$ sendo apresentados na forma de média e valores médios. As amostras de água foram classificadas em 'de acordo' ou 'em desacordo', seguindo a interpretação baseada no valor médio encontrado e o resultado comparado ao Valor Máximo Permitido (V.M.P.) pela legislação do CONAMA n 357/2005 (classe III) (BRASIL, 2005), conforme tabela a seguir:

Tabela 1: Parâmetros e valor máximo permitido (V.M.P) conforme exigência da Resolução do Conselho Nacional do Meio Ambiente (CONAMA) $n^{\circ} 357 / 2005$, classe III.

\begin{tabular}{|l|l|}
\hline Parâmetro & Valor Máximo Permitido \\
\hline Oxigênio dissolvido & Não inferior a $4 \mathrm{mg} / \mathrm{L}$ \\
\hline Temperatura $\left({ }^{\circ} \mathrm{C}\right)$ & - \\
\hline $\mathrm{pH}$ & 6,0 a 9,0 \\
\hline Turbidez (UNT) & Até $100 \mathrm{UNT}$ \\
\hline Cor (mg Pt-Co L-1) & Até $75 \mathrm{mg}$ Pt-Co L-1 \\
\hline Cloreto total $\left(\mathrm{mg} \mathrm{L}^{-1}\right)$ & $250 \mathrm{mg} \mathrm{L}-1$ \\
\hline Ferro dissolvido $\left(\mathrm{mg} \mathrm{L}^{-1}\right)$ & $5,0 \mathrm{mg} \mathrm{L-1}$ \\
\hline Sólidos dissolvidos totais (SDT) (mg L-1) & $500 \mathrm{mg} \mathrm{L-1}$ \\
\hline Coliformes totais (UFC 100 $\mathrm{mL}-1)$ & - \\
\hline Coliformes termotolerantes (UFC $100 \mathrm{~mL}-1)$ & Até 1000 UFC $100 \mathrm{~mL}-1$ \\
\hline
\end{tabular}

Fonte: Adaptado de Brasil (2005). 


\section{RESULTADOS}

Os parâmetros físico-químicos e microbiológicos são determinantes nas características da água, garantindo que a mesma possa ser consumida sem qualquer risco, de forma segura e confiável (RICHTE et al., 2013). É por meio de parâmetros físico-químicos que se pode verificar o quanto determinado curso hídrico é modificado pela ação direta e/ou indireta de substâncias que, para seu uso, pode precisar de um tratamento complexo seu uso (VON SPERLING, 2005). As 19 amostras de água coletadas e analisadas, provenientes de açudes, utilizadas para a dessedentação animal nas propriedades rurais representam 14 municípios (39\%) da região do Vale do Taquari. Os resultados da determinação dos parâmetros físicoquímicos e microbiológicos descritos anteriormente são apresentados nas Tabelas 2 e 3.

Tabela 2: Média e valor médio dos parâmetros físico-químicos analisados nas amostras de águas de açudes localizados em propriedades rurais produtoras de leite provenientes do Vale do Taquari, Rio Grande do Sul, Brasil.

\begin{tabular}{|c|c|c|c|c|c|c|c|c|}
\hline \multirow{2}{*}{ Amostra } & $\begin{array}{l}\text { Oxigênio } \\
\text { dissolvido }\end{array}$ & $\begin{array}{l}\text { Temperatura } \\
\text { (ㅇ) }\end{array}$ & $\mathrm{pH}$ & Turbidez & Cor & Cloretos & Ferro & $\begin{array}{l}\text { Sólidos dissolvidos } \\
\text { totais (mg L-1 })\end{array}$ \\
\hline & (mg L-1) & & & (UNT) & $\begin{array}{l}\text { (mg Pt-Co } \\
\left.\mathrm{L}^{-1}\right)\end{array}$ & (mg L-1) & $\begin{array}{l}\text { (mg L- } \\
\text { 1) }\end{array}$ & \\
\hline 1 & 6,3 & 26,1 & 2,9 & 102 & 0 & 20 & 0,25 & 116,6 \\
\hline 2 & 3,4 & 25,7 & 7,1 & 62,7 & 0 & 20 & 0 & 86,6 \\
\hline 3 & 5,6 & 23,9 & 8,5 & 119 & 0 & 30 & 4 & 193,3 \\
\hline 4 & 1,6 & 24,7 & 7,1 & 19,7 & 0 & 20 & 0 & 166,6 \\
\hline 5 & 3,3 & 23,3 & 8,8 & 0,9 & 6,4 & 20 & 0 & 73,3 \\
\hline 6 & 9,3 & 16,6 & 8,2 & 2,8 & 17,5 & 30 & 0 & 163,3 \\
\hline 7 & 6,5 & 20,9 & 8,5 & 265 & 0 & 30 & 0 & 303,3 \\
\hline 8 & 9 & 21,1 & 8,3 & 32,3 & 35,7 & 40 & 1,5 & 153,3 \\
\hline 9 & 7,5 & 22,7 & 8,2 & 12,2 & 45,9 & 50 & 0 & 226,6 \\
\hline 10 & 6,7 & 17,9 & 7,4 & 225 & 0,2 & 70 & 1 & 526,3 \\
\hline 11 & 7 & 19,4 & 6,8 & 111 & 0 & 40 & 1 & 260 \\
\hline 12 & 10,8 & 20,2 & 8,8 & 267 & 0 & 60 & 1 & 516,6 \\
\hline 13 & 4,9 & 21,2 & 6,7 & 198 & 0 & 20 & 1 & 330 \\
\hline 14 & 6,5 & 23,2 & 6,7 & 30,2 & 60,8 & 20 & 0 & 230 \\
\hline 15 & 6,5 & 16,6 & 6,8 & 94,6 & 0 & 40 & 0 & 366,6 \\
\hline 16 & 4,7 & 17,4 & 7,2 & 5,3 & 81,2 & 20 & 0 & 40 \\
\hline 17 & 3,7 & 17,2 & 6,7 & 87,2 & 0 & 130 & 4 & 293,3 \\
\hline 18 & 4,9 & 13,4 & 7,3 & 322 & 0 & 40 & 0,25 & 313,3 \\
\hline 19 & 5,8 & 13,5 & 6,9 & 43,6 & 0 & 80 & 0 & 276,6 \\
\hline $\begin{array}{l}\text { Valor } \\
\text { médio }\end{array}$ & 6 & 20,3 & 7,3 & 105,3 & 13 & 41,1 & 0,74 & 244 \\
\hline
\end{tabular}

Analisando os resultados médios para cada parâmetro analisado indicaram que os coliformes termotolerantes (3606 UFC $100 \mathrm{~mL}^{-1}$ ) e a turbidez (105,3 UNT) estão em desacordo com a lei em vigor e os valores médios dos demais parâmetros estão de acordo com a legislação. Fazendo-se uma análise geral de cada um dos parâmetros analisados frente as amostras de água dos açudes das propriedades, ferro e cloreto estão dentro do que é estipulado por lei. No entanto, os outros parâmetros como oxigênio dissolvido (21\%), $\mathrm{pH}(5,3 \%)$, turbidez $(42,1 \%)$, cor $(5,3 \%)$, sólidos dissolvidos totais $(10,5 \%)$ e coliformes termotolerantes $(68,4 \%)$ estão em desacordo.

A qualidade da água deve atender aos parâmetros estabelecidos por legislações vigentes, a fim de satisfazer às exigências de saúde pública (SILVA FILHO, 1999), portanto é imprescindível verificar a qualidade da água de determinado corpo hídrico (D’AGUILA, 1996), ainda mais aquela água destinada para a dessedentação dos animais envolvidos na cadeia produtiva do leite. 
Tabela 3. Média e valor médio dos parâmetros microbiológicos analisados nas amostras de águas de açudes localizados em propriedades rurais produtoras de leite provenientes do Vale do Taquari, Rio Grande do Sul, Brasil.

\begin{tabular}{|l|l|l|}
\hline Amostra & $\begin{array}{l}\text { Coliformes totais } \\
\text { (UFC 100 } \mathbf{~ L}^{-1} \text { ) }\end{array}$ & $\begin{array}{l}\text { Coliformes termotolerantes } \\
\text { (UFC 100 } \mathbf{~ L}^{-\mathbf{1}} \text { ) }\end{array}$ \\
\hline 1 & 6453 & 1573 \\
\hline 2 & 13866 & 4800 \\
\hline 3 & 6587 & 3733 \\
\hline 4 & 6373 & 400 \\
\hline 5 & 2373 & 1920 \\
\hline 6 & 3093 & 640 \\
\hline 7 & 5787 & 1173 \\
\hline 8 & 4853 & 3893 \\
\hline 9 & 9413 & 5040 \\
\hline 10 & 17733 & 16293 \\
\hline 11 & 5573 & 2720 \\
\hline 12 & 11173 & 5600 \\
\hline 13 & 1040 & 133 \\
\hline 14 & 7867 & 5813 \\
\hline 15 & 9520 & 8080 \\
\hline 16 & 0 & 0 \\
\hline 17 & 3840 & 720 \\
\hline 18 & 7813 & 5627 \\
\hline 19 & 2320 & 347 \\
\hline Valor médio & 6614,6 & 3605,5 \\
\hline & & \\
\hline
\end{tabular}

\section{DISCUSSÃO}

Os autores Von Sperling (2005), Alves (2010) e Libânio (2010) afirmam que o potencial hidrogeniônico (pH) é uma concentração de íons hidrogênio em uma determinada solução, e esse parâmetro é fundamental em um processo de monitoramento da água, além disso é utilizado para mensurar o grau de acidez e/ou de alcalinidade de uma amostra (HERMES et al., 2004). Os valores para o pH nas amostras de água proveniente de açudes no Vale do Taquari variaram de 2,9 a 8,8, atingindo uma média de 7,3 mg L-1. Segundo Von Sperling (2005) valores abaixo de 7,0 e próximos a 0 indicam aumento de acidez e valores na escala de 7,0 a 14,0 indicam aumento da alcalinidade. A Resolução do CONAMA no 357/2005 (BRASIL, 2005) determina valores entre 6,0 e 9,0 para dessedentação animal, sendo exigido um tratamento simplificado desta água. Portanto, a Amostra 1 está em desconformidade com o valor atribuído.

Brito et al. (2005) ao avaliar a qualidade da água de açudes em Petrolina e Ouricurí (PE) e Canudos e Uauá (BA), verificou em seu estudo que em todas as amostras analisadas o $\mathrm{pH}$ estava de acordo com o valor permitido pela legislação, nas amostras localizadas em Pernambuco os valores ficaram na faixa de 7,4 a 8,0 e na Bahia variaram de 6,5 a 7,8 sendo consideradas neutras, os açudes são utilizados para consumo humano e animal.

No estudo de Pereira Júnior et al. (2011) ao diagnosticar a qualidade da água da lagoa Bela Vista no município de Cuité (PB) os resultados mostraram que mostrou que as amostras analisadas estão em conformidade com a legislação. Mesmo que os índices de pH obtidos na lagoa Bela Vista se encontram em conformidade, estavam próximos do limite máximo permitido pela legislação, variando de 8,4 a 8,6, similar aos resultados obtidos no Vale do Taquari. Os mesmos autores afirmaram que é fundamental haver monitoramento do local e efetivação de ações corretivas que possam vir a reduzir o pH, já que a maioria dos organismos aquáticos sobrevivem com o pH entre 5,0 e 9,0. 
O oxigênio dissolvido (OD) é indispensável à vida de seres aeróbios, valores de OD próximo a 0 podem extinguir determinados organismos aquáticos (VON SPERLING, 2005), ou seja, quanto mais oxigênio tiver no açude melhor será a qualidade da água. Os valores para o oxigênio dissolvido nas amostras de água proveniente de açudes no Vale do Taquari variaram entre 1,6 e 9,3 $\mathrm{mg} \mathrm{L}^{-1}$, atingindo a média de $6,0 \mathrm{mg} \mathrm{L}^{-1}$. Segundo a Resolução do CONAMA no 357/2005 (BRASIL, 2005) as águas doces de classe III devem apresentar os valores de oxigênio dissolvido maiores que $4 \mathrm{mg} \mathrm{L}^{-1}$.

Lima et al. (2009) ao caracterizar a água de açudes com peixes no semiárido pernambucano, observaram que o oxigênio dissolvido (OD) dos açudes 1 e 2 apresentaram valores dentro da faixa de sobrevivência para peixes. Os menores valores foram encontrados no início das coletas de cada ano e os maiores valores foram encontrados no período de julho, para o açude 2, e no período de julho e agosto, no açude 1. Segundo os autores essas oscilações ocorrem devido à mudança de temperatura durante o ano: quanto menor a temperatura, maior será a quantidade de oxigênio dissolvido. No Vale do Taquari não se percebeu essa alteração nos níveis de oxigênio na água dos açudes analisados.

O parâmetro turbidez é responsável por identificar a presença de partículas em suspensão (constituídas por plânctons, bactérias, algas, argilas, silte em suspensão e detritos orgânicos) na água, gerada pela matéria em suspensão, impedindo a passagem de luz, elevadas concentrações de turbidez deixa a água turva, compromete o ecossistema aquático, uma vez que reduz a fotossíntese da vegetação aquática (MACEDO, 2001; LENZI et al., 2009).

Segundo a resolução do CONAMA no 357/2005 (BRASIL, 2005) às águas doces de classe III devem apresentar padrões de turbidez de até 100 UNT. Ao considerar a Tabela 1, observa-se que os valores da turbidez encontrados nos açudes no Vale do Taquari variaram entre 0,9 a 322 UNT, atingindo uma média de 105 UNT, ou seja quase 50\% das amostras analisadas estão com valores acima do permitido, bem como o valor médio encontrado para o parâmetro turbidez. Existe relação entre o parâmetro cor, turbidez e coliformes, ou seja, a turbidez pode ser afetada pela presença de microrganismos em geral, assim, quanto maior a turbidez, maior será o aumento de matéria orgânica na água e consequentemente maior as chances de contaminação por coliformes (VON SPERLING, 2005; CORDEIRO, 2008).

O parâmetro cor nas amostras de água de açudes no Vale do Taquari variaram de 0 a 81,20 mg L-1 $\mathrm{Pt}$-Co, atingindo uma média de $13,0 \mathrm{mg} \mathrm{L}^{-1} \mathrm{Pt}$-Co. Os compostos orgânicos que conferem cor às águas naturais são provenientes da decomposição de matéria orgânica vegetal, resultado do metabolismo de microrganismos presentes no solo e das atividades antrópicas (LIBÂNIO, 2010).

Segundo a Resolução do CONAMA no357/2005 (Brasil, 2005) as águas doces de classe III devem apresentar padrões de cor de até $75 \mathrm{mg} \mathrm{L}^{-1} \mathrm{Pt}-\mathrm{Co}$, embora a média das amostras enquadra-se no permitido, 5,3\% das amostras apresentaram resultados acima do estabelecido. No açude Buri-Frei Paulo (SE) estudado por Barreto et al. (2010) a cor variou de $0,046 \mathrm{mg} \mathrm{L}^{-1} \mathrm{Pt}$-Co no ponto FP01 a 0,059 $\mathrm{mg} \mathrm{L}^{-1} \mathrm{Pt}$-Co no ponto FP03 (período de seca) e de 0,085 $\mathrm{mg} \mathrm{L}^{-1} \mathrm{Pt}-\mathrm{Co}$ no ponto FP02 a mg L-1 Pt-Co no ponto FP01 (período chuvoso), portanto, os valores enquadram-se à legislação vigente. 
As impurezas presentes na água contribuem para o aumento de sólidos na água, são importantes, pois representa o quanto uma rocha pode ser se desgastado (intemperismo), ações antrópicas, como o despejo de esgoto doméstico e uso do solo para plantio favorece a quantidade de sólidos dissolvidos totais na água (VON SPERLING, 2005). Os valores para sólidos dissolvidos totais (SDT) encontrados nos açudes no Vale do Taquari variaram de 40 a 526,33 $\mathrm{mg} \mathrm{L}^{-1}$, atingindo uma média de $244 \mathrm{mg} \mathrm{L}^{-1}$.

A Resolução do CONAMA no 357/2005 (BRASIL, 2005) permite que os sólidos dissolvidos totais em águas doces de classe III apresentem padrões de até $500 \mathrm{mg} \mathrm{L}^{-1}$. Dessa forma, as amostras 10 e 12 das amostras estudadas no Vale do Taquari não estão em conformidade, um dos fatores que possa estar relacionado ao elevado teor de SDT são as áreas de plantio nos piquetes onde há o gado, com acesso livre aos açudes. O estudo de Brito et al. (2005) investigou a qualidade da água de açudes em Petrolina e Ouricurí $(\mathrm{PE})$ e Canudos e Uauá (BA), diagnosticando que uma das amostras de sólidos dissolvidos totais atingiu o valor de máximo de 665,4 $\mathrm{mg} \mathrm{L}^{-1}$ (Uauá/BA), similar aos encontrados no Vale do Taquari, estando também em desconformidade com o que solicita a lei.

A análise microbiológica de coliformes é um importante indicador na qualidade de um corpo hídrico (GARCIA et al., 2006). Os coliformes totais são considerados um grupo de bacilos Gram-negativos, aeróbios ou anaeróbios facultativos, não formadores de esporos, oxidase-negativa, capazes de crescer na presença de sais biliares ou outros compostos ativos de superfície, com propriedades similares de inibição de crescimento, e que fermentam a lactose com produção de ácidos, aldeídos e gás a 35 ㄷ em 24 a 48 horas. Bactérias da família Enterobacteriaceae e dos gêneros Klebsiellla, Escherichia e Serratia constituem esse grupo (CONSOLI et al., 2006). Esses microrganismos não são indicadores de contaminação fecal, pois neste grupo existem bactérias que podem ser encontradas nas fezes e no ambiente. Enquanto que os coliformes termotolerantes são bactérias capazes de desenvolver e/ou fermentar a lactose com produção de gás a 44으 em 24 horas (PELCZAR JUNIOR et al., 2005; BETTEGA et al., 2006). Escherichia coli é o principal representante do grupo dos coliformes termotolerantes, sendo habitante exclusivo do trato gastro-intestinal de animais de sangue quente e é, portanto, indicador de matéria fecal (VON SPERLING, 2005).

Os valores para coliformes totais e termotolerantes (E. Coli) encontrados nas amostras de água provenientes de açudes no Vale do Taquari variaram de 0 a 17733 e de 0 a $16293 \mathrm{UFC} \mathrm{mL}^{-1}$, atingindo uma média de 6614,6 e de $3605,5 \mathrm{UFC} \mathrm{mL}^{-1}$, respectivamente. Os resultados da amostra $\mathrm{n}^{\circ} 10$ para coliformes termotolerantes mostrou-se aproximadamente 16,3 vezes maior do que é exigido pela legislação. Já a amostra 16 não apresentou coliformes totais. A Resolução do CONAMA no 357/2005 (BRASIL, 2005) permite que o valor para coliformes termotolerantes para águas doces de classe III apresentem padrões de até 1000 UFC $\mathrm{mg} \mathrm{L}^{-1}$, elevados níveis de coliformes na água representam poluição e risco à saúde pela presença de organismos patogênicos (MACEDO, 2001). Além disso, grande parte da contaminação dos cursos da água é resultado das fezes de origem de animais de sangue quente em contato direto com o fluxo de água, White et al. (2001) encontrou maior acúmulo de fezes e urina no local próximo a água e uma distribuição mais uniforme no restante do piquete de pastoreio. 
O estudo realizado por Barreto et al. (2010) sobre a qualidade da água dos açudes Carira e Buri (SE) todos os pontos de coletas do açude Buri apresentaram presença de coliformes termotolerantes (E. Coli) de $350 \mathrm{NMP} / 100 \mathrm{~mL}$, estando a água imprópria para consumo humano, porém ainda nos padrões para à dessedentação animal. O diagnóstico da qualidade da água da lagoa Bela Vista no município de Cuité (PB), realizado por Pereira Júnior et al. (2011) encontrou valores altos para os coliformes termotolerantes de 110 a $2400 \mathrm{NMP} / 100 \mathrm{~mL}$ e $1892 \mathrm{NMP} / 100 \mathrm{~mL}$, a partir do resultado diagnosticado fica evidente que a água está imprópria para a dessedentação de animais. O mesmo foi verificado no Vale do Taquari, valores altos, superiores ao diagnosticado nos estudos apresentados, uma vez que é comum o uso de açude para a dessedentação animal. Estudo realizado por Zerwes et al. (2015) evidenciaram valores preocupantes para coliformes totais e E. Coli em poços no município de Imigrante, localizado no Vale do Taquari, esses poços profundos apresentaram contaminação por fezes e essas águas são consumidas sem qualquer método de desinfecção pela população, dessa forma, pode acarretar em riscos à saúde de quem a utiliza para o consumo.

A fim de melhorar a qualidade da água dos açudes, é necessário realizar um tratamento da água (simples ou complexo), uma medida simples envolve um processo de filtragem da água e outra medida seria o uso de cloro (AMORIM et al., 2001). Analisando os resultados médios para cada parâmetro analisado indicaram que os coliformes termotolerantes (3606 UFC $100 \mathrm{~mL}^{-1}$ ) e a turbidez (105,3 UNT) estão em desacordo com a lei em vigor e os valores médios dos demais parâmetros estão de acordo com a legislação.

\section{CONCLUSÕES}

Por meio das análises físico-químicas e microbiológicas foi possível constatar que quase todas as amostras de água analisadas $(n=14)$ estão impróprias para a dessedentação animal. As análises microbiológicas confirmam a possibilidade de contaminação de esgoto ou fezes de animais de sangue quente nas amostras analisadas. É necessário realizar periodicamente o monitoramento desses locais e tomar medidas preventivas como o uso de cloro e de filtros para melhorar o padrão de qualidade dos açudes. Além disso, há necessidade de elaboração e execução de um programa de educação ambiental, para capacitar e conscientizar os produtores rurais no que diz respeito ao manejo e qualidade das águas.

\section{REFERÊNCIAS}

ALVES, C.. Tratamento de águas de abastecimento. 3 ed. Porto: Publindústria, 2010.

AMARAL, L. A.; NADER FILHO, A.; ROSSI JUNIOR, O. D.; FERREIRA, F. L. A.; BARROS, L. S. S.. Água de consumo humano como fator de risco à saúde em propriedades rurais. Revista de Saúde Pública, v.37, n.4, p.510-514, 2003. DOI: http://dx.doi.org/10.1590/S0034-89102003000400017

AMORIM, M. C. C.; PORTO, E. R.. Avaliação da Qualidade Bacteriológica das Águas de Cisternas: Estudo de Caso no Município de Petrolina - PE. In: SIMPÓSIO BRASILEIRO DE CAPTAÇÃO DE ÁGUA DE CHUVA, 3. Anais. Campina Grande: ABCMAC, 2001
AOAC. Association of Official Analytical Chemistry. Official methods of analysis. $16 \mathrm{ed}$. Arlington: AOAC International, 1995.

BARRETO, P. R.; GARCIA, C. A. B.. Caracterização da qualidade da água do açude Buri-Frei Paulo/SE. Scientia Plena, Aracaju, v.6, n.9, p.01-21, 2010. DOI: http://dx.doi.org/10.18571/acbm.111

BETTEGA, J. M. P. R.; MACHADO, M. R.; PRESIBELLA, M.; BANISKI, G.; BARBOSA, C. A.. Métodos analíticos no controle microbiológico da água para consumo humano. Ciência e 
Agrotecnologia, Lavras, v.30, n.5, p.950-954, 2006. DOI: http://dx.doi.org/10.1590/S1413-70542006000500019

BRASIL. Conselho Nacional do Meio Ambiente. Resolução no 357. Brasília: DOU, 2005

BRITO, L. T. L.. Avaliação da qualidade das águas de açudes nos municípios de Petrolina e Ouricurí (PE) e Canudos e Uauá (BA): estudo de caso. In: SIMPÓSIO BRASILEIRO DE CAPTAÇÃO E MANEJO DE ÁGUA DE CHUVA, 9. Anais. Teresina, 2005

CERQUEIRA, M. M. O.; PICININ, L. C. A.; FONSECA, L. M.; SOUZA, M. R.; LEITE, M. O.; PENNA, C. F. A. M.. Qualidade da água e seu impacto na qualidade microbiológica do leite. In: Perspectivas e avanços da qualidade do leite no Brasil. Goiânia: Talento, 2006. p.273-290.

COIMBRA, P. A. D.. Aspectos Extrínsecos do Comportamento de Bebida de Bovinos em Pastoreio. Dissertação (Mestrado em Agrossistemas) - Universidade Federal de Santa Catarina, 2007.

CONSOLI, M. A. F.; BRAGA, M. J. S.; FREITAS, S. L.; AMORIM, P. S.; BATALHA, A. A.; DORNELES, S.. Estudo introdutório sobre o uso de Petrifilm como meio base para a utilização de membrana filtrante na análise de água. Revista Analytica, Rio de Janeiro, n.25, p.70-75, 2006.

CORDEIRO, W. S.. Alternativas de tratamento de água para comunidades rurais. Dissertação (Mestrado em Engenharia Ambiental) - Centro Federal de Educação Tecnológica Celso Suckow da Fonseca, Campos dos Goytacazes, 2008.

D'AGUILA, P.. Pseudomonas aeruginosa como indicador em análises bacteriológicas de águas de abastecimento público. Dissertação de Mestrado (Mestrado em Saneamento Ambiental) - Fundação Oswaldo Cruz, Rio de Janeiro, 1996.

DIAS, M.. Qualidade da água e desempenho dos bovinos: Informe Técnico Macal Nutrição Animal. Campo Grande, 2006.

ECKHARDT, R. R.; SILVEIRA, C. A.; REMPEL, C.. Evolução temporal do uso e cobertura da terra do município de Bom Retiro do Sul-RS-Brasil. Revista Caminhos da Geografia, Uberlândia, v.14, n.47, p.150-161, 2013.

FUNASA. Fundação Nacional da Saúde. Manual Prático de análise de água. Brasília, 2004.

GARCIA, C. A. B.; ALVES, J. P. H.. Qualidade da água. Relatório de Pesquisa - LQA/UFS. In: Diagnóstico e avaliação da sub-bacia hidrográfica do Rio Poxim. São Cristóvão, 2006.

HELLER, L.; PÁDUA, V. L.. Abastecimento de Água para Consumo Humano. Belo Horizonte: UFMG, 2006.

HERMES, L. C.; SILVA, A. S.. Avaliação da Qualidade das Águas: Manual Prático. Brasília: Embrapa Informação Tecnológica, 2004.

IBGE. Instituto Brasileiro de Geografia e Estatística. Censo Agropecuário 2006. Rio de Janeiro: IBGE, 2006.
IBGE. Instituto Brasileiro de Geografia e Estatística. Estatísticas Cidades. Rio de Janeiro: IBGE, 2015.

LENZI, E.; FAVERO, L. O. B.; LUCHESE, E. B.. Introdução à química da água: ciência, vida e sobrevivência. Rio de Janeiro: LTC, 2009.

LIBÂNIO, M.. Fundamentos de qualidade e tratamento de água. 3 ed. Campinas: Átomo, 2010.

LIMA, W. S.; GARCIA, C. A. B.. Qualidade da água em Ribeirópolis/SE: o açude do cajueiro e a barragem do João Ferreira. Scientia plena, Aracaju, v.4, n.12, 2008.

LIMA, V. T. A.; CAMPECHE, D. F. B.; PEREIRA, L. A.. Caracterização da água de açudes com peixes no semiárido pernambucano. Revista Acadêmica Ciências Agrárias Ambiental, Curitiba, v.7, n.4, p.395-405, 2009.

MACEDO, J. A. B.. Águas \& águas: métodos laboratoriais de analises físico-químicas e microbiológicas. Juiz de Fora: Jorge Macedo, 2001.

NASCIMENTO, R. M.. Estimativa de volume de água em açudes para irrigação da cultura orizícola em Santa Margarida do Sul. Relatório de Estágio (Curso de Engenharia Florestal), Universidade Federal do Pampa, São Gabriel, 2012.

PELCZAR JUNIOR, J. M.; CHAN, E. C. S.; KRIEG, N. R. Microbiologia: conceitos e aplicações. 2 ed. São Paulo: Makron Books, 2005.

PEREIRA, R. S.. Poluição hídrica: Causas e consequências. Revista Eletrônica de Recursos Hídricos, Porto Alegre, v.1, n.1, p.20-36, 2004

PEREIRA JÚNIOR, L. R.; ALVES, G. S.; GAMA, J. S. N.. Diagnóstico da qualidade da água da lagoa Bela Vista no município de Cuité. Engenharia Ambiental, Espírito Santo do Pinhal, v.8, p.46-61, 2011.

SILVA FILHO, S. V.. Avaliação da qualidade bacteriológica das águas utilizadas em unidades de saúde do Estado de Pernambuco. In: CONGRESSO BRASILEIRO DE MICROBIOLOGIA, 26. Anais. Salvador,1999.

RICHTER, C. A.; AZEVEDO NETO, J. M.. Tratamento de água: tecnologia atualizada. São Paulo: Edgard Blücher, 2013.

RUZANTE, J. M.; FONSECA, L. F. L.. Água: mais um fator para atingir a qualidade do leite. Revista Batavo, v.8, n.108, p.40 42, 2001.

VON SPERLING, M.. Introdução à Qualidade das Águas e Tratamento de Esgotos. 3 ed. Belo Horizonte: Universidade Federal de Minas Gerais, 2005.

TAVARES, J. E.; BENEDETTI, E.. Água: uso de bebedouros e sua influência na produção de bovinos em pasto. Cadernos de Pós-Graduação da FAZU, Uberaba, v.2, n.1, p.1-6, 2012.

WHITE, S. L.; SHEFFIELD, R. E.; WASHBURN, S. P.; KING, L. D. GREEN JUNIOR, J. T.. Spatial and time distribution of dairy cattle excreta. Journal of Environmental Quality, v.30, p.3036,2001 
ZERWES, C. M.; SECCHI, M. I.; CALDERAN, T. B.; BORTOLI, J.;

TONETTO, J.; TOLDI, M.; CONCEICAO, E. O.; SANTANA, E. R.

R.. Análise da qualidade da água de poços artesianos do município de Imigrante, Vale do Taquari/RS. Ciência e

Natura, Santa Maria, v.37, p.651-663, 2015.

A CBPC - Companhia Brasileira de Produção Científica (CNPJ: 11.221.422/0001-03) detém os direitos materiais desta publicação. Os direitos referem-se à publicação do trabalho em qualquer parte do mundo, incluindo os direitos às renovações, expansões e disseminações da contribuição, bem como outros direitos subsidiários. Todos os trabalhos publicados eletronicamente poderão posteriormente ser publicados em coletâneas impressas sob coordenação da Sustenere Publishing, da Companhia Brasileira de Produção Científica e seus parceiros autorizados. Os (as) autores (as) preservam os direitos autorais, mas não têm permissão para a publicação da contribuição em outro meio, impresso ou digital, em português ou em tradução. 